Running head: DESIGNING FOR ONLINE COMPUTER-BASED SIMULATIONS 1

\title{
DESIGNING FOR ONLINE COMPUTER-BASED CLINICAL SIMULATIONS: EVALUATION OF INSTRUCTIONAL APPROACHES
}

Ilana Dubovi ${ }^{1,2}$

${ }^{1}$ Department of Instructional Technology and Learning Sciences, Utah State University.

${ }^{2}$ The Cheryl Spencer Department of Nursing, University of Haifa. 


\begin{abstract}
Background: Online computer-based simulations are becoming more widespread in nursing education. Therefore, an understanding of when and how to implement the variety of instructional strategies related to these simulations is fundamental.

Objectives: This study compares the effectiveness of online computer-based simulations designed using two alternative instructional approaches-Productive Failure and Simple-to-Complex sequencing — on learning of clinical reasoning skills.
\end{abstract}

Participants: Participants in this study were undergraduate nursing students $(n=103$, mean age $=$ 23.4 \pm 2.1 ) enrolled at a university in Israel.

Methods: Participants completed two online simulations designed using Productive Failure approach (emergency medicine, mental health) and two online simulations using Simple-toComplex approach (cardiovascular health, pediatrics). Pre- and post-test clinical reasoning evaluations were administered prior to and immediately following each simulation.

Results: Clinical reasoning learning gains were significantly higher for online simulations designed with the Simple-to-Complex approach than simulations designed with Productive Failure approach $(\mathrm{F}(3,288)=9.656, \mathrm{P}<0.001)$. Students devoted significantly more time $(\mathrm{F}(1,102)=$ $260.15, \mathrm{P}<0.001)$ and more attempts $(\mathrm{F}(1,102)=167.39, \mathrm{P}<0.001)$ in learning with Simple-toComplex simulations than they did with Productive Failure simulations. The amount of time that students were engaged in learning with simulations was significantly associated with learning gains scores.

Conclusions: This study proposes that well-designed online simulations can improve nursing students' clinical reasoning. The Simple-to-Complex approach was found to be more efficient than Productive Failure for online learning. Learning with Simple-to-Complex approach was 
Running head: DESIGNING FOR ONLINE COMPUTER-BASED SIMULATIONS 3

behaviorally more engaging and students' achievements were higher, which implies that instructional process facilitates learning, and therefore have to be taken in consideration by nurse educators. Integration of computerized educational modalities within nursing education is discussed.

Keywords: Computerized simulations, Online simulations, Nursing education, Productive Failure, Clinical reasoning, Instructional design

\section{INTRODUCTION}

Simulations provide a safe, low-stakes environment for students to practice new skills and apply new knowledge. There is a strong evidence that the use of simulations can help students achieve identified learning objectives while increasing their self-confidence and satisfaction, enhancing their decision-making, and improving learning outcomes related to patient safety (Cant and Cooper, 2017; Cook et al., 2011). As a result, promising efforts have been made in the nursing domain involving the creation of a variety of simulations for practicing skills in a broad range of professional activities. In recent years, mannequin simulations (low- to high-fidelity patient simulations) have become increasingly popular educational tools. These simulations are "an attempt to replicate some or nearly all of the essential aspects of a clinical situation so that the situation may be more readily understood and managed when it occurs for real in clinical practice" (Morton, 1995, p. 76). The National Council of State Boards of Nursing report suggests that simulations can be used as a substitution for up to $50 \%$ of traditional clinical experiences as long as certain conditions are met during implementation (Hayden, et al., 2014).

However, although mannequin patient simulations are becoming widely accepted as an adjunct to actual clinical practice, several challenges and limitations that have been identified as preventing many nursing schools from using these platforms, including financial challenges and 
limited access to on-campus clinical laboratories, (Dean, Williams \& Balnaves, 2017; Lapkin and Levett-Jones, 2011; Nagle et al., 2008). With the advancement of online technologies, the development of clinical reasoning and skills among students and practitioners from healthcare disciplines no longer needs to be confined to classrooms and laboratories (Webb et al., 2017). An online, computer-based simulation can provide a mechanism to train large numbers of nursing students, engaging them as active participants in any geographic location at any time of day. Computerized simulations have the unique advantage of allowing students to observe and manipulate otherwise unobservable phenomena, such as molecular interactions. Further, a recent meta-analysis that compared both high- and low-fidelity simulations to computer-based simulation, proposed that computer-based simulation is the most effective approach for promoting nurses' knowledge and skills (Hegland, et al., 2017).

In light of these findings, we must recognize the need for additional evaluation of the effectiveness of learning with online computerized simulations. Moreover, further information is needed about instructional design of such environments to support students learning.

\section{Instructional Approaches for Computer-based Simulations Design}

Instructional design is the systematic process of planning events to facilitate learning (Gagne et al., 2005). Instructional theorists argue that a well-designed instructional process activates learners' internal cognitive structures and increases the likelihood of successful learning. Instructional pathways of learning can be operationalized in a variety of forms, which result in qualitatively different instructional approaches. Educational literature suggests two apparently contradictory instructional approaches-Simple-to-Complex and Productive Failure.

The Simple-to-Complex (S2C) approach assumes that novice learners benefit from fullyguided, simple components that gradually build up to a more complex, whole-task structure (Van 
Merriënboer et al., 2003). A detailed, step-by-step sequence of instruction that increases in complexity may provide an opportunity to strengthen knowledge before proceeding to more complex tasks, which some argue reduces intrinsic cognitive load ${ }^{1}$. In addition, S2C design contains learning tasks that are in the students' zone of proximal development and that reduce the probability of encoding of errors and misconceptions). Hence, this learning approach has positive effects on learning, performance, and motivation (Van Merrienboer and Sweller, 2005).

In contrast to the $\mathrm{S} 2 \mathrm{C}$ approach, a Productive Failure (PF) approach proposes beginning the learning process with complex challenges that are beyond learners' current skills and abilities (Kapur, 2008; Kapur and Bielaczyc, 2012; Schwartz et al., 2011). PF is characterized by students exploring the problem, struggling, and even failing before guidance is provided in the knowledge assembly phase. Several scholars and research programs have spoken about the role of failure in learning, suggesting that having novices try and fail at tasks can support more flexible learning skills and be productive for deeper understandings (Kapur, 2008; 2012; 2014; Jacobson et al., 2017). These scholars have proposed theoretical mechanisms of effective learning with PF that include the activation of prior knowledge, which in turn prepares students for deeper learning and, as a result, enhances transfer performance.

Considering the relevance of these two alternative instructional approaches, $\mathrm{S} 2 \mathrm{C}$ and $\mathrm{PF}$, to the design of online computer-based simulations, this study investigates and compares the effectiveness of each of these strategies on learning achievements.

\footnotetext{
1 An instructional theory based on knowledge of human cognitive architecture which specifically addresses the limitation of working memory (Pass and Sweller, 2014). There are three categories: 1. Intrinsic cognitive load caused by the natural complexity of the biologically secondary information that must be processed; 2. Extraneous cognitive load caused by instructional design; 3. Germane cognitive load refers to working memory resources that are devoted to dealing with intrinsic cognitive load rather than to the extraneous, thus facilitating learning.
} 


\section{$\underline{\text { Research questions: }}$}

1. What impact does learning with online computer-based simulations have upon the students' clinical reasoning?

2. How effective at fostering nursing students' clinical reasoning are online simulations designed using Productive Failure and Simple-to-Complex approaches?

3. How does instructional approach affect students' behavioral engagement (operationalized as time devoted to the learning process and attempts to retry the module; Fredricks et al., 2004) while learning with computer-based online simulation?

\section{METHODS}

\section{$\underline{\text { Research Design }}$}

Research design was within-group pre- and post-test, time-series design using a quantitative approach.

\section{Participants and Procedure}

Participants were undergraduate nursing students at University of Haifa in Israel ( $n=103 ; 31$ males, 72 females; mean age $=23.4 \pm 2.1$ ) who had not yet started their clinical practicum. Between October 2016 and October 2017, participants completed online clinical simulations covering four topic areas: emergency medicine, mental health, cardiovascular health, and pediatric medicine. The emergency and the mental health simulations were designed using PF; the cardiovascular and the pediatric simulations were designed with S2C. Students were required to complete all of the simulations individually within 6 hours. Pre- and post-test evaluations were administered immediately prior to and following each simulation.

The study was conducted following the approval of University of Haifa ethics committee. 


\section{Data Collection Instruments}

\section{SimNurse Environment}

National League for Nursing (NLN) made a statement that "Simulation can take many forms, including human patient simulation (using manikins and/or standardized patients), virtual and computer-based simulations..." (2015). Herein, SimNurse, represents the computerized-based simulations platform that was created for this study with the goal of enabling students to practice clinical reasoning in a remote, simulated environment (The Cheryl Spencer Department of Nursing, 2013). SimNurse integrates a variety of educational e-learning tools designed to provide multiple clinical online experiences - case study scenarios with virtual patients, games, virtual mentoring, self-assessment tools, 3D visualizations, interactive videos, digital-dynamic tools for exploration, and biochemical models for discovery learning (e.g., Dubovi et al., 2017a; Dubovi et al., 2018). These online learning experiences are embedded within a learning management system (LMS) that enables tracking, reporting and delivering the internetbased simulations and that can be accessed from any computer at any time. SimNurse experiences are assembled in modules in accordance with the students' clinical rotations. This study evaluated four SimNurse modules: pediatric and cardiovascular simulations that were designed with the S2C approach; and mental health and emergency modules that were designed with the PF approach.

The S2C approach incorporates components of knowledge that are explicitly decomposed into simplified subcategories and then gradually combined through authentic, case-based scenarios. For example, the cardiovascular module begins with three basic coronary care units: 1 . anatomy and physiology of the cardiovascular system, 2. cardiac cycle and electrocardiogram (ECG) waveforms, and 3. recording and interpretation of ECG. The final module integrates the differentiated units of cardiovascular knowledge into a case-based, clinical scenario (see Figure 
1a). Hence, the components of knowledge build upon each other through hierarchical nesting relationships whereby the simpler components of knowledge are nested within more sophisticated, case-based problems.

In contrast to the $\mathrm{S} 2 \mathrm{C}$ approach, $\mathrm{PF}$ incorporates the holistic, case-based scenarios from the very beginning. This approach confronts learners with case-based scenarios in which components of knowledge from within and across multiple domains are embedded and are not explicitly defined. For example, in a scenario involving a pregnant woman with a mood disorder, students are asked to make decision regarding her physical and mental condition and, after delivery, assess the health of her infant. Given the complexity of clinical problems, a variety of supports were provided, including reflection prompts, question prompts, content support and an opportunity for knowledge assembling and consolidation by comparing and contrasting learners' solutions with the target knowledge and skills (see Figure 1b). 
a.

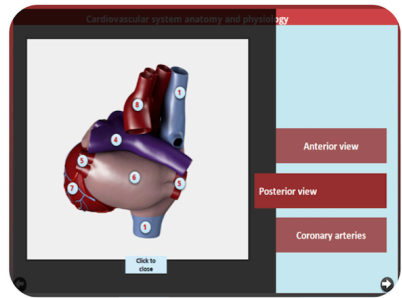

Anatomy unit
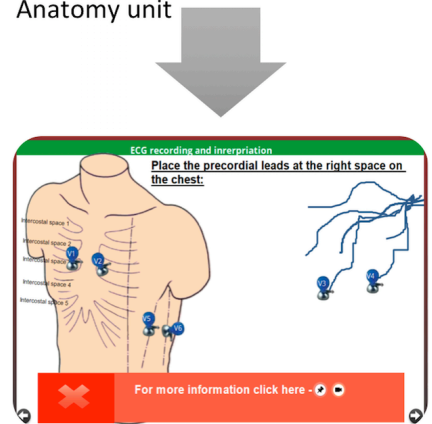

ECG practice with feedback

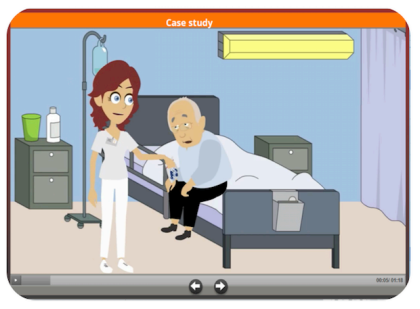

Complex

clinical

scenario b.
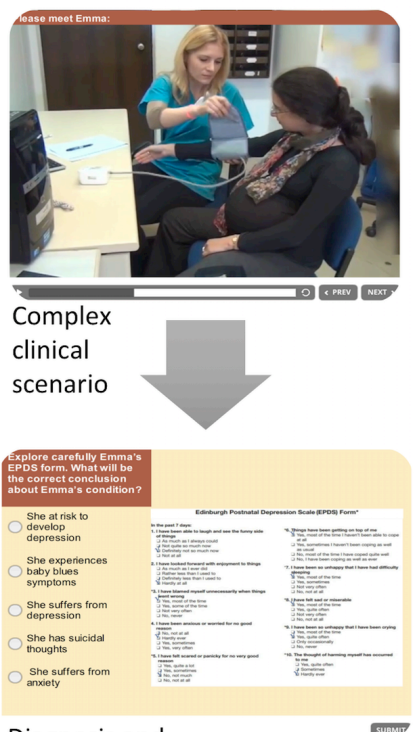

Diagnosis and information sensitizing

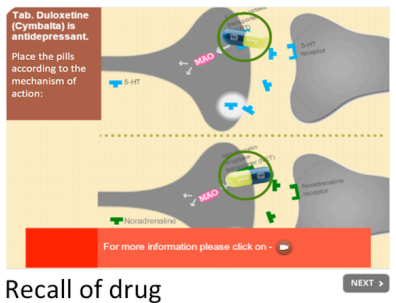

mechanisms with

feedback

Figure 1. Screenshots of SimNurse clinical simulations.

a. Flow of cardiovascular simulation that was designed with the S2C approach - anatomy and physiology integrated into ECG interpretation and recording and then into complex scenario.

b. Flow of mental-health simulation with PF approach-scaffolds are provided for knowledge consolidation.

\section{Clinical reasoning evaluation tool}

The Clinical Reasoning Evaluation (CRE) tool was developed by the author to assess students' clinical reasoning related to the following clinical topics: cardiovascular, pediatric, emergency, and mental-health. CRE items are multiple-choice and based on licensing examinations for the Registered Nurses Department of the Israeli Nursing Administration. In addition, the items were reviewed by experienced lecturers in the university nursing department to ensure appropriate 
alignment of context and content and a suitable level of expertise. The tool incorporates questions according to the Five Rights of Clinical Reasoning model (the right cues; the right action; the right patients; the right time; and the right reason) that was proposed by Levett-Jones, et al. (2010). An example of question that refers to the identification and prioritizing of the "right patient" in need is: "Which of the following infants has a developmental delay: a 3-month-old who doesn't roll over; a 2-month-old who doesn't laugh loud; a 1-year-old who doesn’t grasp objects with palmar grasp; a 15-month-old who doesn't have bowel and bladder control". Another example for "right cues" recognition is: "ECG of a 48-year-old patient for the last three days presents ST depression. The patient has pain in his lower jaw, cold sweating, his heart rate is 110 . Analyzing those symptoms may lead you to conclude that the patient suffers from: Aortal stenosis; Stable angina; Unstable angina; Acute MI.”

CRE items are grouped by clinical topics. The emergency topic evaluates two dimensions: 14 items that refers to head injury multiple trauma and 6 items to burns. The mental health topic evaluated 10 items related to mood disorders and psychotic disorders. The cardiovascular topic included 10 items related to systematic ECG interpretation and different coronary conditions. The emergency topic evaluates two main dimensions: 10 items related to diagnosis and treatment of young patients with type 1 diabetes and 10 items about child development. Analysis of the CRE tool using Cronbach alpha yielded a good internal consistency score of 0.65 .

\section{Demographic questionnaire}

The student demographic questionnaire requested information about the participant's gender, age and ethnicity. 


\section{Students' $\log S$}

Students logs were collected to assess the learning engagement process and view an individual student's activity in particular simulation. The amount of time students devoted learning each clinical simulation was measured, and the number of attempts were counted.

\section{$\underline{\text { Statistical Analysis }}$}

Students responses to items in the CRE were coded as correct or incorrect, and the total score was calculated as the percentage of correct answers. The pre- and post-test results, including the overall score for the simulation clinical topic and its domains, were analyzed with descriptive statistics (Mean, SD) and compared using a paired $t$-test.

To compare between the simulations, gain scores for each participant were calculated following each of the clinical simulation as: (post-test score) - (pre-test score). Interaction effects between the simulation instructional approach were evaluated using repeated measures ANOVAs. The Pearson correlation coefficient was calculated when appropriate. The effect size was then compared against guidelines of effect size measures (Cohen, 1988). Data were analyzed using SPSS (version 24, IBM Corporation, Armonk, NY). 


\section{RESULTS}

Results of the pre- and post-test CRE scores are presented in Table 1, arranged according to clinical topics and the instructional approach. The post-tests across all topics are significantly higher than the pre-tests, with large effect size of Cohens's $d$ (Cohen, 1988).

\section{Table 1}

Comparisons of pre-test and post-test CRE scores and learning gains according to clinical topics and instructional strategy $(\mathrm{N}=103)$

\begin{tabular}{|c|c|c|c|c|c|}
\hline \multirow{2}{*}{$\begin{array}{l}\text { Instructional } \\
\text { design }\end{array}$} & \multirow[t]{2}{*}{ Simulation clinical topics: } & \multirow{2}{*}{$\begin{array}{l}\text { Pre-test } \\
\text { scores }\end{array}$} & \multirow{2}{*}{$\begin{array}{l}\text { Post-test } \\
\text { scores }\end{array}$} & \multicolumn{2}{|c|}{ Statistical tests } \\
\hline & & & & Paired $t$ test & $\begin{array}{c}\text { Effect } \\
\text { size, } \\
\text { Cohen's d }\end{array}$ \\
\hline \multirow{5}{*}{$\begin{array}{l}\text { Productive failure } \\
\text { design }\end{array}$} & Emergency overall (20 items) & $54 \pm 13$ & $67 \pm 11$ & $-8.21 * * *$ & 1.01 \\
\hline & Emergency domains: & & & & \\
\hline & Multiple trauma (14) & $53 \pm 15$ & $67 \pm 13$ & $-7.52 * * *$ & 0.96 \\
\hline & Burns (6) & $57 \pm 20$ & $66 \pm 19$ & $-3.49^{* *}$ & 0.47 \\
\hline & Mental health (10 items) & $62 \pm 20$ & $74 \pm 14$ & $-5.36 * * *$ & 0.72 \\
\hline \multirow{5}{*}{$\begin{array}{l}\text { Simple to } \\
\text { complex design }\end{array}$} & Cardiovascular (10 items) & $45 \pm 17$ & $70 \pm 18$ & $-10.75^{* * *}$ & 1.38 \\
\hline & Pediatrics overall (20 items) & $60 \pm 17$ & $84 \pm 10$ & $-13.84 * * *$ & 1.68 \\
\hline & Pediatrics domains: & & & & \\
\hline & Type 1 diabetes $(10)$ & $62 \pm 19$ & $87 \pm 11$ & $-12.093^{* * *}$ & 1.57 \\
\hline & Child development (10) & $58 \pm 20$ & $81 \pm 13$ & $-10.118^{* * *}$ & 1.35 \\
\hline
\end{tabular}

${ }^{*}$ Data are presented in percentage mean $\pm \mathrm{SD}$, Range $0-100$.

$* * \mathrm{p}<.01, * * * \mathrm{p}<.001$

In order to compare the learning with the two instructional strategies, $\mathrm{PF}$ and $\mathrm{S} 2 \mathrm{C}$, learning gains (post-test - pre-test) were calculated for each clinical topic separately (see Figure 2). One-way, repeated measures ANOVA with a Greenhouse-Geisser correction revealed a significant interaction effect of the instructional methods on learning gains $(\mathrm{F}(3,288)=9.656, \mathrm{P}<0.001)$, with partial $\eta^{2}=0.09$ (small-medium effect size). Bonferroni post hoc tests showed that learning gains 
were significantly higher with the Cardiovascular and Pediatric clinical simulations, which were designed with the S2C approach, than Emergency and Mental health simulations, which were designed with the PF approach $(\mathrm{p}<0.001)$.
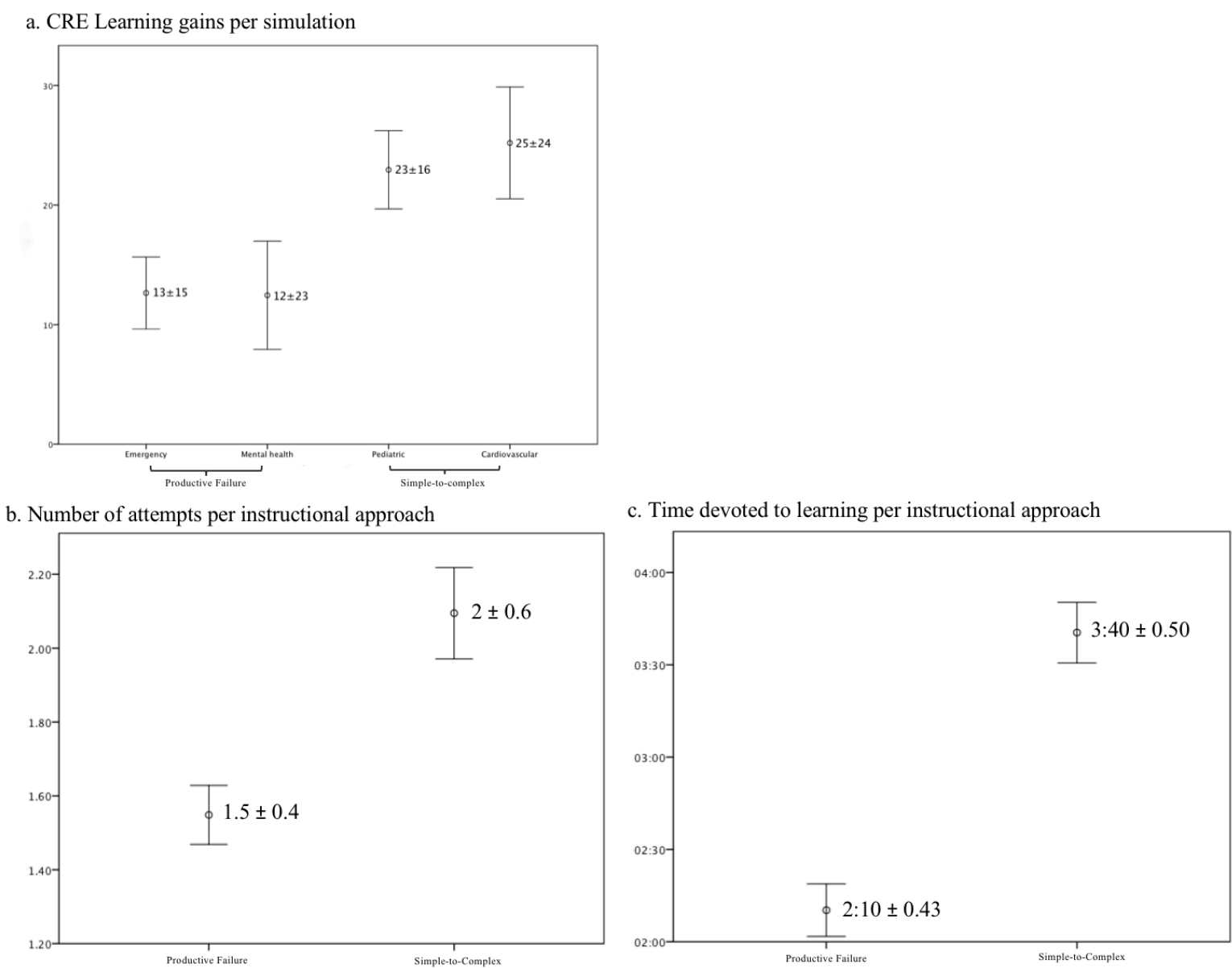

Figure 2. Analysis of learning with the two instructional approaches.

a. CRE Learning gains' means and SD for the clinical topic of computer-based simulations and for their instructional approach.

b. Number of attempts to retry the modules compared by the simulation instructional approach.

c. Time students devoted to learning compared by the simulation instructional approach.

The amount of time students devoted to learning with each clinical simulation and the frequency of their attempts were measured and analyzed. A significant though small correlation was found between the overall time that that students devoted to learning with the simulations and the learning 
gains (Pearson $r=0.201 ; p<0.05$ ). No significant correlations were found between number of attempts and students learning gains. When comparing the two instructional strategies, a significant difference was found between the time students spend $(\mathrm{F}(1,102)=260.15, \mathrm{P}<0.001$ with partial $\left.\eta^{2}=0.72\right)$ and number of attempts $\left(F(1,102)=167.39, \mathrm{P}<0.001\right.$ with partial $\left.\eta^{2}=0.62\right)$

(Figure $2 b, c)$. More specifically, students were significantly more behaviorally engaged in learning with simulations that were designed with S2C approach.

\section{DISCUSSION}

Online computer-based simulations that incorporate variety of educational technology represent a relatively new chapter in nurse education. The current study aimed to evaluate the use of online simulations on nursing students' clinical reasoning. Our results clearly show that online simulations significantly support learning of clinical reasoning. It is important to stress that the content that was presented to students during the online simulations, such as interpretation of ECG, had been previously taught to all participants within previous obligatory courses. Hence, learning with computer-based resources as videos and mixed-media interactive material helps students to integrate their prior knowledge with the applied knowledge and therefore reinforce the learning processes. These findings are consistent with the nursing literature reports. Several studies into nursing research found that students' achievements after learning with well-designed, computerbased simulations were higher than with traditional lecture-based instruction (e.g., Dubovi et al., 2017b; McMullan, Johes \& Lea, 2010; Moule et al., 2008; Öztürk \& Dinç, 2014). Furthermore, numerous studies that compared learning with computer-based simulations to mannequin-based simulations revealed that online simulations are at least as good as mannequin-based simulations in teaching clinical knowledge and reasoning (Arnold et al., 2013; Durmaz, et al., 2012; Hegland et al., 2017). 
To reinforce students' learning processes with computerized learning environments, an understanding of when and how to implement the variety of instructional design principles is fundamental. Two opposing instructional designs, the Productive Failure and Simple-to-Complex approaches, were evaluated in this study. The findings of the current study revealed that students who learned with computer simulations designed with the S2C instructional approach gained significantly more than students who learned with PF approach. The literature suggests inconsistent findings, while there is evidence that support the PF approach (e.g., Kapur and Bielaczyc, 2012), there are also studies that support findings of this study that gradually increasing in complexity (i.e. S2C approach) is more efficient for learning of procedural skills in school settings (Likourezos and Kalyuga, 2017; Loibl and Rumme, 2014) and in medical education (Chen, et al., 2015; Haji et al., 2016).

Findings of this study underline the superiority of the S2C approach and can be interpreted through the instructional consequences on cognitive load. Instructional theorists such as Sweller et al. (1998) argue that a well-designed instructional process activates learners' internal cognitive structures, such as working memory, and increases the likelihood of successful learning. Cognitive load theory states that intrinsic cognitive load should be optimized in instructional design by selecting materials that match the learner's prior knowledge or proficiencies (Sweller et al., 1998; van Merriënboer and Sweller, 2005, 2010). A growing body of research shows that learning through progressively increased complexity (i.e. S2C approach) demands less mental effort than PF and, hence, reduces cognitive load resulting in more robust learning (Haji et al., 2016; Likourezos and Kalyuga, 2017; Pollock et al, 2002). An additional explanation for the diminished results with PF approach can be explained by the conditions of the current study, which evaluated individual learning while majority of studies that evaluated PF 
approach are based on collaborative learning as a mechanism that enriches the process of problem solving (Kapur and Bielaczyc, 2012; Scardamalia and Bereiter, 2003). Moreover, current study evaluated an online learning. Literature reports differences between the traditional, face-to-face classroom setting and self-regulated, online learning, particularly the lack of an immediately available instructor and the need for a certain level of technology skills that can elevate mental efforts (Mayer, 2014; van Merriënboer and Ayres, 2005).

Understanding students' learning process with online clinical simulations can shed additional light on the superiority of the S2C instructional approach. Empirical research repeatedly confirms that students' level of engagement is associated to academic achievements (D'Melloet al., 2017; Finn and Zimmer, 2012; Pekrun and Linnenbrink-Garcia, 2012), a finding that was reconfirmed by the results of this study. More specifically, the results show that the more students behaviorally engage in a learning process, namely the more time they devote to learning, the higher their learning gains were. Comparison between the two instructional strategies through analysis of students' log files, revealed that students interacted significantly longer with the content to be learned when simulations were designed with the $\mathrm{S} 2 \mathrm{C}$ approach as opposed to the $\mathrm{PF}$ approach. Students also tended to spend more time and effort making additional attempts with modules that were designed with S2C approach. Thus, this analysis makes clear when students decided to spend more time which may explain the superior performance with the S2C approach compared to the PF approach.

\section{Limitations:}

The present study has several limitations. Assignment of conditions in this study was not randomized. All participants were recruited from among the students in one nursing department. To evaluate the advantages of learning with online computer-based simulations, further work 
should be performed on a larger scale with different categories of healthcare providers (e.g., registered nurses) including incorporation and evaluation of debriefing technics.

\section{Conclusion:}

This study proposes that well-designed, online simulations can be an additional, authentic learning strategy that improve clinical reasoning. The online modality proposes flexible, affordable, and accessible means to train and actively engage large numbers of nursing students. Moreover, implementation of powerful educational technology in nursing education can provide greater opportunities for deliberate practice and for self-recognition of any potential errors before professional nursing skills are required in a real patient care setting. Computational interactive visualizations and dynamic multimedia can also reinforce nursing students' understandings of health sciences by integrating it into clinical assessment data and relating to dynamic and complex patient conditions. Integration of these educational modalities within nursing education can help our profession to move forward.

Future studies should further explore the differences in learning processes between online simulations and face-to-face simulations comparing collaborative and individual learning using qualitative and quantitative methods. 


\section{ACKNOWLEDGMENTS}

I am grateful to Dr. Efrat Dagan and Dalit Wilhelm for their major contributions to the foundation and establishment of the SimNurse unit at The Cheryl Spencer Department of Nursing, University of Haifa, as well as for their support. I am especially grateful to Carol Ravid, Mor Saban, Orly Tonkikh and Dalit Lahav who participated and contributed from their time, effort and their creativity to the design the of SimNurse simulations. I appreciate and thank the nursing students who voluntarily participated in this research, and whose insights helped to improve the SimNurse simulated environment.

I thank Dr. Abigail Phillips and Mr. Joel Drake for their careful language editing.

\section{REFERENCES}

Arnold, J. J., Johnson, L. M., Tucker, S. J., Chesak, S. S., Dierkhising, R. A., 2013. Comparison of three simulation-based teaching methodologies for emergency response. Clinical Simulation in Nursing, 9(3), e85-e93.

Cant, R. P., \& Cooper, S. J. (2017). Use of simulation-based learning in undergraduate nurse education: An umbrella systematic review. Nurse education today, 49, 63-71.

Chen, R., Grierson, LE., Norman, GR., 2015. Evaluating the impact of high- and lowfidelity instruction in the development of auscultation skills. Medical Education, 49 (3), 276-85.

Cohen, J., 1988. Statistical Power Analysis for the Behavioral Sciences (2. Auflage). Hillsdale, NJ: Erlbaum.

Cook, D. A., Hatala, R., Brydges, R., Zendejas, B., Szostek, J. H., Wang, A. T., ... Hamstra, S. J., 2011. Technology-enhanced simulation for health professions education: a systematic review and meta-analysis. Jama, 306(9), 978-988. 
Dean, S., Williams, C., \& Balnaves, M., 2017. Living dolls and nurses without empathy. Journal of advanced nursing, 73(4), 757-759.

D'Mello, S., Dieterle, E., Duckworth, A., 2017. Advanced, analytic, automated (AAA) measurement of engagement during learning. Educational Psychologist, 52(2), 104-123.

Dubovi, I., Levy, S.T., Dagan, E., 2017a. Now I know how! The learning process of medication administration among nursing students with non-immersive desktop virtual reality simulation. Comput. Educ. 113, 16-27.

Dubovi, I., Levy, S.T., Dagan, E., 2017b. Situated Simulation-Based Learning Environment to Improve Proportional Reasoning in Nursing Students. Int. J. Sci. Math. Educ. 119.

Dubovi, I., Dagan, E., Sader-Mazbar, O., Nasar, L., Levy, S.T., 2018. Nursing Students Learning with Complexity-Based Computerized Models the Pharmacology of Diabetes Mellitus: A Quasi-Experimental Study. Nurse Educ. Today 61, 175-181.

Durmaz, A., Dicle, A., Cakan, E., Cakir, S., 2012. Effect of screen-based computer simulation on knowledge and skill in nursing students' learning of preoperative and postoperative care management: a randomized controlled study. CIN: Computers, Informatics, Nursing, 30(4), 196-203.

Fredricks, J. A., Blumenfeld, P. C., Paris, A. H., 2004. School engagement: Potential of the concept, state of the evidence. Review of Educational Research, 74, 59-109.

Finn, J. D., Zimmer, K. S., 2012. Student engagement: What is it? Why does it matter? In Handbook of research on student engagement (pp. 97-131). Springer US. 
Gagné, R. M., Wager, W. W., Golas, K. C., Keller, J. M., 2005. Principles of Instructional Design (5th ed.). Belmont, CA: Wadsworth/Thomson Learning.

Haji, F. A., Cheung, J. J., Woods, N., Regehr, G., Ribaupierre, S., Dubrowski, A., 2016. Thrive or overload? The effect of task complexity on novices' simulation-based learning. Medical education, 50(9), 955-968.

Hegland, P. A., Aarlie, H., Strømme, H., \& Jamtvedt, G., 2017. Simulation-based training for nurses; systematic review and meta-analysis. Nurse Education Today, 54, 6-20.

Hayden, J. K., Smily, R. A., Raij, A., Kardong-Edgren, S., Jeffries, P. R., 2014. The NCSBN national simulation study: A longitudinal, randomized, controlled study replacing clinical hours with simulation in prelicensure nursing education. Journal of Nursing Regulation, 5(2) (Supplement).

Jacobson, M. J., Markauskaite, L., Portolese, A., Kapur, M., Lai, P. K., Roberts, G., 2017. Designs for learning about climate change as a complex system. Learning and Instruction. $52,1-14$

Kapur, M. 2008. Productive failure. Cognition and instruction, 26(3), 379-424.

Kapur, M., Bielaczyc, K., 2012. Designing for productive failure. The Journal of the Learning Sciences, 21(1), 45-83.

Kapur, M. 2014. Productive failure in learning math. Cognitive Science, 38(5), 1008 1022.

Lapkin, S., Levett-Jones, T., 2011. A cost-utility analysis of medium vs. high-fidelity human patient simulation manikins in nursing education. Journal of Clinical Nursing, 20(23-24), 3543-3552. 
Levett-Jones, T., Hoffman, K., Dempsey, J., Jeong, S. Y. S., Noble, D., Norton, C. A., ... Hickey, N., 2010. The 'five rights' of clinical reasoning: An educational model to enhance nursing students' ability to identify and manage clinically 'at risk'patients. Nurse education today, 30(6), 515-520.

Likourezos, V., Kalyuga, S., 2017. Instruction-first and problem-solving-first approaches: alternative pathways to learning complex tasks. Instructional Science, 45(2), 195-219.

Loibl, K., \& Rummel, N., 2014. The impact of guidance during problem-solving prior to instruction on students' inventions and learning outcomes. Instructional Science, 42(3), 305-326.

Mayer, R. E., 2014. The Cambridge Handbook of Multimedia Learning. New York: Cambridge University Press.

McMullan, M., Jones, R., \& Lea, S. (2010). Patient safety: numerical skills and drug calculation abilities of nursing students and registered nurses. Journal of Advanced Nursing, 66(4), 891-899.

Morton, P. G., 1995. Academic education. Creating a laboratory that simulates the critical care environment. Critical Care Nurse, 16(6), $76 \mathrm{e} 8$.

Moule, P., Albarran, J. W., Bessant, E., Brownfield, C., \& Pollock, J. (2008). A nonrandomized comparison of e-learning and classroom delivery of basic life support with automated external defibrillator use: A pilot study. International Journal of Nursing Practice, 14(6), 427434.

Öztürk, D., \& Dinç, L. (2014). Effect of web-based education on nursing students' urinary catheterization knowledge and skills. Nurse Education Today, 34(5), 802-808. 
Running head: DESIGNING FOR ONLINE COMPUTER-BASED SIMULATIONS 22

Nagle, B. M., McHale, J. M., Alexander, G. A., French, B. M., 2009. Incorporating scenario-based simulation into a hospital nursing education program. The Journal of Continuing Education in Nursing, 40(1), 18-25.

National League for Nursing (NLN), (2015). A vision for teaching with simulation. Retrieved from: http://www.nln.org/docs/default-source/about/nln-vision-series-(position$\underline{\text { statements)/vision-statement-a-vision-for-teaching-with-simulation.pdf?sfvrsn=2 }}$

Pass, F. Sweller, J., 2014. Implications of Cognitive Load Theory for Multimedia Learning. In R. E. Mayer (Eds.), The Cambridge handbook of multimedia learning, (pp. 39-54). New York, NY: Cambridge University Press.

Pollock, E., Chandler, P., Sweller, J., 2002. Assimilating complex information. Learning and instruction, 12(1), 61-86.

Pekrun, R., Linnenbrink-Garcia, L. (2012). Academic emotions and student engagement. In Handbook of research on student engagement (pp. 259-282). Springer US.

Scardamalia, M., Bereiter, C., (2003). Knowledge Building. In J. W. Guthrie (Ed.), Encyclopedia of education (pp. 1370-1373). New York, NY: Macmillan Reference.

Schwartz, D. L., Chase, C. C., Oppezzo, M. A., Chin, D. B., 2011. Practicing versus inventing with contrasting cases: The effects of telling first on learning and transfer. Journal of Educational Psychology, 103(4), 759-775.

Sweller, J., van Merrie“nboer, JJG., Paas, F., 1998. Cognitive architecture and instructional design. Educ Psychol Rev 10, 251-96.

The Cheryl Spencer Department of Nursing (2013). SimNurse: platform for nursing education and training, University of Haifa, http://simnurse.haifa.ac.il 
Running head: DESIGNING FOR ONLINE COMPUTER-BASED SIMULATIONS 23

Van Merriënboer, J. J., Kirschner, P. A., Kester, L., 2003. Taking the load off a learner's mind: Instructional design for complex learning. Educational psychologist, 38(1), 5-13.

Van Merriënboer, J. J. G., Ayres, P. 2005. Research on cognitive load theory and its design implications for e-learning. Educational Technology Research and Development, 53(3), $5-13$.

Van Merriënboer, J. J., Sweller, J., 2005. Cognitive load theory and complex learning: Recent developments and future directions. Educational psychology review, 17(2), 147-177.

Van Merriënboer, J. J., Sweller, J., 2010. Cognitive load theory in health professional education: design principles and strategies. Medical education, 44(1), 85-93.

Webb, L., Clough, J., O'Reilly, D., Wilmott, D., Witham, G., 2017. The utility and impact of information communication technology (ICT) for pre-registration nurse education: a narrative synthesis systematic review. Nurse Education Today 48 (1), 160-171. 